Revista de la red interuniversitaria de estudios sobre las literaturas rioplatenses contemporáneas en Francia

19 | 2018

La rebelión de los hijos: el judaísmo en la literatura latinoamericana contemporánea entre tradición y asimilación

\title{
La rebelión de hijos emancipados: judeidad y diáspora en escritores exiliados judíos latinoamericanos
}

Leonardo Senkman

CpenEdition

Edición electrónica

URL: http://journals.openedition.org/lirico/6140

DOI: $10.4000 /$ lirico.6140

ISSN: 2262-8339

Editor

Réseau interuniversitaire d'étude des littératures contemporaines du Río de la Plata

Referencia electrónica

Leonardo Senkman, «La rebelión de hijos emancipados: judeidad y diáspora en escritores exiliados judíos latinoamericanos », Cuadernos LIRICO [En línea], 19 | 2018, Puesto en línea el 26 enero 2019, consultado el 20 abril 2019. URL : http://journals.openedition.org/lirico/6140 ; DOI : 10.4000/ lirico.6140

Este documento fue generado automáticamente el 20 abril 2019.

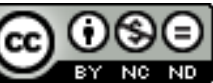

Cuadernos LIRICO está distribuido bajo una Licencia Creative Commons Atribución-NoComercialSinDerivar 4.0 Internacional. 


\title{
La rebelión de hijos emancipados: judeidad y diáspora en escritores exiliados judíos latinoamericanos
}

\author{
Leonardo Senkman
}

1 La propuesta de reflexionar para el campo intelectual judeo-latinoamericano "la rebelión de los hijos" con la que Stéphane Mosès define el rechazo de la tradición de normas y valores judíos desde la Emancipación europea constituye un fértil desafío. A tal fin, me propongo explorar los diferentes rumbos del proceso de Emancipación en América Latina y su impacto sobre la inmigración judía, a fin de comprender mejor los dilemas identitarios que afrontaron la generación nativa de intelectuales cuyas respectivas rebeliones fueron muy diferentes a aquella rebelión de los hijos europeos de padres judíos emancipados (Mosès 1997).

2 El doble movimiento de asimilación y recuperación de lo judío en intelectuales europeos que analiza Mosès es muy diferente de la experiencia judía latinoamericana, en la cual los momentos de rebelión para los hijos nativos corresponden a una etapa tardía de la emancipación de los inmigrantes: la rebelión de esa generación nativa estallará luego de su decisión de integrarse a la ciudadanía de los países latinoamericanos, rechazando la extranjería de sus padres. En Europa fueron los padres de Kafka, Benjamin y Scholem quienes se asimilaron buscando la integración a la modernidad mientras sus hijos se rebelaban para disasimilarse.

La rebelión del joven argentino nativo David contra la furia de su padre Scholem -el jazan litúrgico del drama Réquiem para un viernes a la noche (1964), de German Rozenmacher, luego que su hijo le anunciara su casamiento con una goye-, no es un conflicto religioso sino cifra el profundo deseo de David de nacionalizarse argentino. David le grita al padre: “¿Qué se guarda en esta casa? Entro aquí y me siento en otro mundo, a mitad de camino de todo. ¡Estoy cansado de hablar mitad en ídish y mitad en castellano! ¡Estoy cansado de vivir en el pasado, estoy cansado de ser un extranjero!" (Rozenmacher 1971: 46)

4 Antes de analizar textos de ambos escritores argentinos mencionados, es menester recordar que la rebelión de los hijos de la Emancipación judía en Europa fue diferente en 
América Latina, tanto porque el proceso de la emancipación jurídica, política y social aconteció de modo distinto en las repúblicas latinoamericanas, así como también porque los padres contra quienes se rebelaron sus hijos nativos eran judíos muy diferentes a los padres de Franz Kafka o Franz Rosenzweig. Los judíos residentes durante generaciones en Europa Occidental y Central en los años previos al proceso de Emancipación, tuvieron que luchar arduamente para poder conseguir los derechos cívicos y beneficios culturales de la Ilustración; muy diferente, en cambio, fue la historia en el Nuevo Mundo de los padres y abuelos inmigrantes de los escritores judíos.

Desde la formación del estado nación liberal, a mediados del siglo XIX, los inmigrantes que fueron llamados por las elites latinoamericanas para modernizar sus países -también a los judíos-, disfrutaron inmediatamente de la igualdad jurídica, la libertad de cultos y de residencia, garantizados por Constituciones libérrimas, sin necesidad de luchar para su emancipación civil y política como ocurrió en Europa.

6 A diferencia del Viejo Mundo donde volvieron a ser aceptados, en los Imperios coloniales ibéricos en América, los judíos estuvieron interdictos, sea en los virreinatos, capitanías generales hispánicas o en las capitanías hereditarias brasileras luso-portuguesas. Esos inmensos territorios coloniales fueron declarados Juderein durante tres siglos de dominio imperial europeo y vigilados por la Inquisición. Al margen de un reducido número de cripto-judíos perseguidos y marranos castigados, no hubo presencia de judíos, quienes legalmente podrán arribar como inmigrantes a las repúblicas latinoamericanas sólo en años posteriores a su independencia de España y Portugal.

Otra fue la historia en Europa. La emancipación jurídica formal se logró al cabo de numerosas batallas políticas y legislativas desde la Revolución Francesa, de modo escalonado y desigual, y muchas veces su resultado apenas fue provisorio. Las políticas de integración y asimilación al estado nación liberal en la Francia del siglo XIX o en la Alemania Guillermina se basaron en la exigencia a las comunidades judías de nacionalización cívica y cultural del judío; en tanto ciudadanos de fe judía, ellos tuvieron que abolir su separación étnica y prerrogativas de autonomía corporativa comunitaria transnacional; más aún: la Emancipación exigió a los judíos europeos la reforma y modernización del culto y la "regeneración moral" por medio de la educación (Girard 1988; Badinter 1989).

8 Ninguna de estas exigencias fueron requeridas en la América Latina católica independiente. En primer término, porque no existían todavía comunidades judías establecidas semejantes a las europeas cuando fueron sancionadas las Constituciones liberales; en segundo término, las olas de inmigrantes judíos y no judíos arribados desde la década de 1880 no procuraron inmediatamente la ciudadanía en esos países de inmigración masiva; su integración nacional estuvo mucho más acotada en nichos específicos de la esfera socio-económica, donde trabajaron como mano de obra para las tareas de modernización de países subdesarrollados. En Argentina, Uruguay, Brasil, Chile, sus Constituciones liberales garantizaban no sólo la libertad de culto a los inmigrantes no católicos: también fue obra de la emancipación latinoamericana modernizadora la separación de la religión del Estado, así como las leyes de secularización que coadyuvaron a legalizar los derechos civiles y cívicos de no católicos. Sin embargo, a pesar de enfrentamientos anticlericales, la secularización de la generación modernizadora liberal del 1880 en Argentina, por ejemplo, no condujo a la separación completa de la Iglesia y el Estado, como ocurrió en Brasil en 1889, en México en 1917, en Uruguay en 1919 y en Chile en $1925 .{ }^{1}$ Pero, a pesar que las sociedades católicas latinoamericanas no legitimaron del 
todo la existencia etno-nacional religiosa de las comunidades judías que empezaban a organizarse, no hubo intolerancia hacia el culto judío. Además, tampoco los inmigrantes y extranjeros temieron que la igualdad jurídica y los valores universales de un humanismo ilustrado hayan estado seriamente amenazados en coyunturas de xenofobia, como ocurrió en Europa a partir de los 1880 con la irrupción en la esfera pública de partidos políticos y movimientos radicales de derecha, anti-modernizantes y abiertamente antijudíos (Karady 2000).

9 Finalmente, existió otra diferencia importante con Europa: pese a que en países eurolatinoamericanos (Argentina, Uruguay o sur de Brasil), poblados con millones de extranjeros, hubo políticas públicas de asimilación nacional de inmigrantes (especialmente la educación pública laica y obligatoria), la secularización no llegó a deslegitimizar completamente las colectividades etno-nacionales. Durante el siglo XIX y las primeras décadas del $\mathrm{XX}$, comunidades inmigratorias organizaron sus iglesias protestantes, como la Iglesia Anglicana -asumiendo la misión de convertirse en un refugio de etnicidad en los inicios del siglo XX en ámbitos rurales (Seiguer 2013).

10 En la heterogénea, multiétnica y racialmente diversa sociedad civil de países sudamericanos la ilegitimidad de la alteridad de los judíos inmigrantes fue mucho menos compulsiva, comparada con la ilegitimidad de la etnicidad e identidad diaspórica que afrontaron los ciudadanos judíos de fe mosaica en Francia o Alemania. La índole colectiva etno-cultural y lingüística de las colonias agrícolas judías, que echaron los cimientos de la comunidad judía argentina, fue reconocida desde el primer momento en que la Jewish Colonization Association (JCA) adquirió más de 600000 hectáreas de tierras privadas, en conformidad con los gobiernos federal y provinciales de la Argentina, para asentar en las pampas a miles de colonos judíos oriundos de Rusia. Los gobernantes argentinos nunca opusieron resistencia a que las colonias de la JCA estuvieran concentradas en extensos territorios rurales de las provincias de Entre Ríos, Santa Fe, Buenos Aires, donde conformaron densas sociedades mayoritariamente judías y con su propio espacio público (Avni 1992: 217-223).

11 La colonización agrícola de inmigrantes católicos, protestantes y judíos apenas fue uno de los mecanismos con que la emancipación en América Latina ayudó al extranjero a acceder a la tierra como chacarero arrendatario y también propietario. La elite liberal en la región de colonias, y en el sur de la provincia argentina de Santa Fe, además, percibió tempranamente durante la década de 1870 que, junto al principio de la libertad de cultos, era necesario apresurar la sanción y vigencia de leyes de registro civil y de matrimonio civil, para coadyuvar a la integración de los extranjeros en la sociedad civil y a la cultura argentinas. El respeto de esas elites liberales a las particularidades religiosas de los diversos grupos étnicos no católicos -especialmente protestantes, pero también judíosreconocía las diferencias culturales propias de las diversas nacionalidades para su integración nacional argentina (Michelletti 2010). No extraña, pues, que en aquel ambiente de triunfo del liberalismo, la sociedad civil argentina reconociera una identidad "hyphenated" judeo-argentina, aún años después que los legendarios gauchos-judíos de Gerchunoff abandonaran el campo y se radicaran en la ciudad. ${ }^{2}$

12 En Europa la situación fue diferente. Victor Karady resume los dilemas de la emancipación afirmando que la asimilación fue la respuesta judía a los procesos de secularización parcial en algunos países, con variantes según se tratase de naciones en la Europa occidental, la central o la oriental. No sólo el proceso emancipatorio transitó andariveles distintos en las diversificadas sociedades del Viejo Mundo, sino además 
estuvo condicionado por las dirigencias judías que respondían de manera diferenciada a los desafíos de la modernidad; unos estaban por la asimilación individual a la nación donde eran ciudadanos, otros a favor del mantenimiento del gueto mientras que judíos iluministas de Europa oriental abogaban por una autonomía colectiva de carácter cultural, en unos casos, o nacional en otros (Karady: 41-45; 70-82).

Arendt subrayaba la paradoja de que, precisamente, aquellos judíos emancipados que disimulaban su origen étnico tras la condición genérica de seres humanos, personificaban a sus ojos la condición del paria en la Modernidad. Pero en países de América Latina, los parias no se encontraban entre gringos inmigrantes pobres y en judíos aceptados aún prejuiciosamente, sino entre los excluidos y marginados de la modernización: indios, gauchos, afroamericanos y criollos desplazados, quienes fueron reemplazados por extranjeros a pesar que no se naturalizaban. ${ }^{3}$ Los únicos parias entre judíos inmigrantes en la Argentina de principios de siglo XX fueron anarquistas, comunistas y luchadores sociales: su paradigma es el legendario Simon Radowitzky, objeto de varios relatos y estudios.(Marti, 2010)

En las emergentes sociedades civiles en proceso de modernización, a los judíos acriollados no se les recordaba permanentemente su origen étnico como a los asimilados judíos europeos, pese a la amenaza de estigmatización, segregación y violencia antisemita que surgieron esporádicamente, al igual que contra otras colectividades etno-nacionales de inmigrantes. Si a los que permanecían fieles a su tradición etno-religiosa les reprochaban en Francia la "condición de extraños" por su resistencia a la integración a la cultura "nacional" jacobina, en cambio, las lealtades étnicas de los inmigrantes a sus Madres Patrias fueron legitimadas en Argentina, Uruguay y Brasil (Senkman 2013: 391-393).

La credencial de mayor prestigio en clave emancipatoria entre intelectuales judíos nativos fue haber profesado un obsesivo interés por la historia y el pensamiento nacional; y a diferencia de casos semejantes entre judíos europeos asimilados y "nacionalizados", en el campo intelectual latinoamericano no fueron acusados esos judíos de "desnaturalizar" la cultura nacional. No obstante, la nacionalización cívica y cultural de ciertos filósofos y escritores judíos de segunda generación, hijos de inmigrantes en América Latina, logró invisibilizar la alteridad judía de su origen familiar inmigratorio; el interés por la historia de sus naciones y del pensamiento de los pueblos autóctonos acaso haya sido una estratagema no solo intelectual de esos filósofos para asimilarse completamente camuflando lo judío familiar.

16 Félix Schwartzmann Turkenich (Santiago, Chile, 1913-2014) nació en el seno de una familia judía rumana inmigrante, realizó sus estudios de filosofía en la Universidad de Chile. En 1949, obtuvo el título de profesor extraordinario de sociología en la Facultad de Filosofía con una tesis sobre antropología filosófica, titulada El sentimiento de lo humano en América: ensayo de antropología filosófica. Schwartzmann desarrolló una amplia reflexión sobre las bases de la convivencia en América Latina, marcada, a su juicio, por el sentimiento de soledad y un impulso frustrado de comunión con el otro. ${ }^{4}$

El filósofo historicista judío argentino, naturalizado mexicano Horacio Cerruti Guldberg (Mendoza, 1950) tuvo que emigrar a Ecuador huyendo de la dictadura militar en 1976, y luego se trasladó a México, donde se naturalizó en 1993; hasta el presente enseña e investiga en la UNAM. Su consigna filosófica y clave de lectura es "Pensar la realidad a partir de la propia historia crítica y creativamente para transformarla" (Cerruti Guldberg 1983, 1986, 1989). Este enunciado teórico, santo y seña del "linaje de la tradición que representa el humanismo cosmopolita de las utopías libertarias latinoamericanas", según 
Gerardo Oviedo, caracteriza toda su producción intelectual, condensando los méritos académicos de Cerruti Guldberg cuando recibió en 2010 el Doctorado Honoris Causa por la Universidad de Varsovia. El fundamento de la distinción subraya que "abordó con suma sagacidad la problemática política, social, cultural y humana de los pueblos que habitan actualmente aquellas tierras, perfecto y esclarecido conocedor de la identidad de los pueblos y habitantes de América Latina". ${ }^{5}$

Diferente de los casos anteriores es la trayectoria del mexicano Enrique Krauze, historiador y biógrafo de héroes culturales y políticos del siglo XIX y de la Revolución Mexicana. Autor de una trilogía de amplia difusión popular de biografías noveladas, Siglo de caudillos. Biografía política de México 1810-1910 (1976), Biografía del poder (1987) y La presidencia imperial (1997), indaga en figuras fundamentales del pasado nacional y revolucionario, incluyendo a presidentes de la república mexicana. Su prestigio intelectual trasciende México: por más de veinte años colaboró con Octavio Paz en la revista Vuelta, de la que fue secretario de redacción y luego subdirector. En 1991 fundó la productora Clío TV y desde 1999 dirige la revista cultural heredera de Vuelta: Letras Libres , que circula en varios países de habla hispana (Krauze 1976, 1977, 1987, 1989, 1992, 1997, 2010).

19 Un rasgo distintivo lo separa de varios literatos e historiadores latinoamericanos: hijo de inmigrantes judíos polacos, Krauze no sólo no oculta el pasado familiar sino ofrece testimonio de la influencia del deber de memoria que aprendió durante la educación en un colegio judío laico mexicano que, según su testimonio, habría pergeñado su oficio de historiador carlyleano de los héroes del pasado mexicano. ${ }^{6}$ Durante muchos años José Vasconcelos fue admirado por Krauze como el mayor héroe cultural de la generación de 1915, junto a Madero; y también fue seducido por la retórica del mestizaje cultural mexicano. En el ensayo "México en clave bíblica", incluido en su De héroes y mitos (2010) libro que caracteriza "una sorprendente historia de la imaginación heroica y bíblica en México desde la Conquista hasta nuestros días"-, Krauze recuerda con regocijo la anécdota de que su hijo León, a los cuatro años y durante la noche pascual del Pesaj, respondió a la pregunta de su abuelo sobre el motivo de la celebración, confundiendo la salida de los judíos de Egipto con la profecía que llevó a los aztecas a fundar su ciudad en la laguna donde estuviera un águila devorando a una serpiente. $\mathrm{Y}$ a fin de legitimar su deber de memoria, evoca el juicio de Luis González y González, uno de sus maestros en El Colegio de México, de quien aprendió la historia del siglo XIX y la época revolucionaria:

En alguna ocasión escribió que si había dos pueblos en donde gravitara el pasado como una obsesión, pueblos -digamos- bendecidos por el pasado pero también lastrados por él, esos pueblos eran el pueblo judío y el pueblo mexicano. De modo que tenía su razón de ser transferir la vocación de recordar, tan propia de la actitud judía ante la vida, a la historia de México (Domínguez Michael 2011).

Finalmente, mediante otro cruce en clave de mestizaje intelectual, el liberalismo moderado de la época de la Reforma es rescatado por Krauze, quien filia su inspiración ideológica liberal en el pensamiento heterodoxo de Spinoza y la tradición del liberalismo mexicano:

Spinoza es una tentación irresistible para el judaísmo secular de todas las épocas, sobre todo de la época después de la Ilustración: es la mejor heterodoxia del judaísmo. Yo me colocaba en esa heterodoxia que empalmaba muy bien con el liberalismo, tanto con el mexicano como con el liberalismo clásico europeo, inglés y francés, y aun español, el de Ortega ( Domínguez Michael 2011). 
21 Ahora bien: a diferencia de la visión liberal de la historia mexicana de Krauze, el proyecto intelectual de los citados filósofos chileno y argentino, revela una voluntad de encomendarse a la historia del pensamiento latinoamericano y vernaculizar la filosofía occidental europea como condición necesaria de rescatar la alteridad radical de los pueblos originarios aborígenes negados por el estado-nación criollo y europeizante. En el intento de pensar una filosofía vernácula conforme a las cosmogonías de los pueblos latinoamericanos, ellos rasuran toda otra alteridad étnica religiosa particular, también la traída por sus padres inmigrantes. El caso Krauze es diferente: él bucea en la historia mexicana con el lente del liberalismo historicista que no le exige reemplazar el logos de la metafísica occidental -tampoco el Davar bíblico- por otro logos nacionalista para redescubrir la alteridad y el pasado de los mexicanos, sus compatriotas. El liberalismo filosófico e histórico inmuniza a Krauze de las acechanzas de la vernaculización y de la asimilación, aunque no de la tentación de un logos "mestizo".

La experiencia de estos intelectuales judíos de segunda generación sugiere una tendencia completamente opuesta a la estudiada por Stéphane Mosés de aquellos filósofos judíos europeos emancipados pero desilusionados de la historia alemana y de una Europa devastada por los nacionalismos beligerantes.

El caso Franz Rosenzweig y su disasimilación para volver al judaísmo es paradigmático por su revuelta anti-historicista desde la filosofía y la teología. Luego de haber concluido en 1914 un riguroso estudio sobre la génesis y el desarrollo del concepto hegeliano de Estado, al término de la Primera Guerra Mundial, Franz Rosenzweig ya no podía suspender el juicio con respecto a la catástrofe bélica y mostrarse indiferente ante los acontecimientos históricos de su tiempo (Roberto Navarrete Alonso, 2015a y 2015b). Mientras que para Rosenzweig la ciencia histórica, cuyo método e ideología de fondo habían sido radicalmente puestos en cuestión por el propio acontecer histórico ${ }^{7}$, en América Latina pocos acaecimientos históricos como el exilio ayudaron a intelectuales judíos asimilados a replantear su condición diaspórica.

El fenómeno en Europa de la disasimilación, como fue llamado por Franz Rosenzweig, resultado de profundas crisis y dislocamientos en la historia social y política, en América Latina también fue experimentado por algunos intelectuales y escritores judíos dislocados obligados a salir al exilio político bajo dictaduras militares (Sznajder y Roniger 2013).

El exilio y destierro sufridos por estos intelectuales en Argentina, Chile, Uruguay y Brasil les despojó de la historia y cultura nacional, provocando un sentimiento de diasporización judía en sus vidas fuera del país natal. La diáspora, esa extraterritorialidad que antes había sido relegada a las antípodas del territorio de la patria por el judío ciudadano, ahora, pertinaz, resurge en el exilio, y en ese no lugar también aparece revalorado el espectro de antiguos éxodos de la familia judía frente a la cual sus hijos nativos se habían rebelado (Roniger, Senkman, Sznajder, Sosnowski, 2017: 173-179).

Sin patria, y muchos despojados de su ciudadanía y con nacionalidad interdicta, estos intelectuales judíos descubren que ahora viven en una diáspora pero sin judaísmo, apenas con esa indefinible ambigüedad que Derrida llamaba “judeidad" (Derrida 2003b). En efecto, en el exilio estos intelectuales disasimilados reinventan lo que entienden por su judeidad, compartiendo con Derrida sin saberlo la convicción no sólo de la inclausurabilidad de la tradición, sino, por el contrario, las inexploradas posibilidades de significación que ella contiene. La judeidad les deja abiertas a estos exiliados diversas formas de 
pertenencia en tensión, incluso la posibilidad de una identidad judía sin pertenencia, tal como Derrida ilustra en relación a la figura del "marrano" (Derrida 2003b).

Un caso interesante de escritor judío argentino a quien el exilio contribuyó a su trabajo de disasimilación es Pedro Orgambide (su nombre completo: Pedro Isaac Gdansky Orgambide), hijo de padre judío y madre española. La emigración y el exilio argentino son evocados por el mismo Pedro Orgambide desde ese no lugar paradigmático y diaspórico: la extranjería. En la trilogía narrativa sobre la memoria que escribió al regresar del exilio mexicano ${ }^{8}$, Orgambide hizo revivir el revés de la trama de la historia de éxodos de su familia emigrante a la Tierra Prometida argentina, los Gdansky, abuelos paternos judíos polacos-rusos, y los Orgambide, abuelos maternos italianos y españoles. Muy significativamente, la última contribución de Pedro Orgambide, publicada un día antes de morir en su columna dominical de Clarín, precisamente fue para recordar al nono, el abuelo italiano, y al zeide, el abuelo judío-polaco. ${ }^{9}$

Luego del retorno de su emigración forzada a México -a donde escapó en 1974 amenazado por la siniestra escuadra para-policial Triple A-, la experiencia exiliar le convenció de la irreversibilidad de la extranjería, aun para él, un tanguero y porteño de ley, autor de celebrados libros sobre cultura y música popular de su amada Buenos Aires. ${ }^{10}$ Vivir y crear en el exilio fue una experiencia fundamental de Pedro Orgambide, quien, al acecho del dislocamiento durante diez años de destierro, reflexionó acerca de la condición judía y del destino de sus ancestros. El escritor de ficciones no casualmente imaginó un destino mestizado de judío errante en fantásticas reencarnaciones del protagonista de su novela Aventuras de Edmund Ziller en tierras del Nuevo Mundo, publicada en México, 1977. ${ }^{11}$ Orgambide empezó a escribir en el exilio, y luego publicó a su regreso en Buenos Aires, no sólo el ciclo narrativo de la memoria -El Arrabal del mundo, Hacer la America y Pura Memoria (1983-85)-; también empezó a escribir "fuera de lugar" sus líricas prosas autobiográficas, Todos teníamos veinte años (1985) y el ensayo Ser argentino (1996), testimonio personal glosado con crónicas históricas. A su regreso de México, Orgambide confiesa en un reportaje: "aprendimos a ser extranjeros" en el exilio:

Creo que en el exilio, todos revivimos de algún modo la experiencia de nuestros abuelos inmigrantes. Aprendimos a ser extranjeros. Comprendimos al nono o al zeide que soñaban con su aldea o con el mar, sentados en la vereda. Fuimos ellos o como ellos, y desde la extranjería entendimos algo de la identidad aluvional del argentino (Orgambide 1999: 156)..$^{12}$

Pero Orgambide aprendió no sólo la extranjeridad del exiliado político: hizo, además, otro aprendizaje como judío de aquello que en 1983, en vísperas de su regreso a la Argentina, denominó "la condena de la diáspora". En la nota publicada ese año sobre un poema de Humberto Costantini (entrañable amigo, hijo de sefardíes italianos, y también exiliado en México), escribió:

La imagen del judío errante aparece con cierta frecuencia en las conversaciones de algunos escritores argentinos, alejados durante estos últimos años de su país de origen. La referencia no es sólo literaria; alude a otro origen, más remoto: a la ascendencia judía de esos escritores. De algún modo, el exilio político parece revivir en ellos, en nosotros, la condena de la diáspora. Pienso en David Viñas o en mí, hijos de matrimonios mixtos, o en Humberto Costantini, argentino de origen italiano, sefardita, autor del poema Eli, Eli, Lamma Sabajtani... (Orgambide 1983: 45; énfasis en el original).

La sensación de extranjería y de vivir en la diáspora, aun después de su regreso a Buenos Aires, Orgambide la condensó en los sentimientos de forastera y convaleciente de la 
protagonista de su novela no casualmente titulada La convaleciente (1987), una recién retornada del exilio. Muy significativamente la novela comienza con la confesión de una enferma que inicia su recuperación: "La enfermedad ha terminado -me dije- y, con ella, la fiebre de nuestra juventud. Lo que importa es recomenzar, seguir viviendo. Pero, ¿cómo?" (Orgambide 1987: 7) La protagonista de La convaleciente expresa su necesidad de tener que explicarse a sí misma y a los que se quedaron con metáforas de extranjería y dislocamiento: "Caminaba por la ciudad como si fuera una extranjera. Era una situación inocente, al fin y al cabo: ésta era mi ciudad. La reconocía, claro que sí. Pero algo mío había muerto en el momento de partir. Y yo buscaba ese algo diez años después, cuando la ciudad y yo no éramos las mismas" (8).

31 La otra metáfora es de enfermedad, contagio y, sobre todo, estado de convalecencia: "Soy una convaleciente -pensé-. Y no puedo explicar a todo el mundo que mi enfermedad no es contagiosa". Los que regresan, dice la convaleciente, "interrumpimos una rutina, cierta continuidad (los cumpleaños, por ejemplo) y éramos como enfermos que regresaran de un inmenso hospital y se instalaran, sin pedir permiso, en medio de la vida que había seguido sin nosotros, a pesar de nosotros" (7). El exilio no se termina al regresar, por el contrario, se transforma en extrañamiento y provisoriedad. La convaleciente vuelve al barrio de la casa de su madre al regresar a Buenos Aires y se siente "como si hubiera invernado durante largo tiempo" (61). Un ex compañero de la Universidad, a fin de explicarle las dificultades de la transición democrática y la situación del país durante los años de Alfonsín, "a cada rato decía la palabra desfasaje", y la convaleciente se sentía

como suspendida en el tiempo, como si los últimos años no hubieran existido. Era una ilusión, sin duda [...]. Esa ilusión tenía algo de perversa: nos hacía creer, a los sobrevivientes, que era posible recomenzar sin que se notaran nuestras cicatrices. Pero no era así. Cada uno llevaba en la cara la ansiedad, la impaciencia por integrarse al mundo que había abandonado. Y también el miedo. Miedo a que no nos quisieran, a ser apartados como leprosos... La nuestra era una peste sin úlceras ni llagas, hecha de recuerdos molestos para quienes, como Alicia, habían vivido de puertas para adentro... (53)

En ese invernadero la exiliada había suspendido la vida confiada en un ineludible regreso a la amada Buenos Aires. Y cuando vuelve, recuerda esas mismas calles del barrio añorado en México, pero que hora le resultan extrañas (80). Por cierto, en la diáspora mexicana, nunca logró sentirse en casa: "Las mudanzas del destierro, ese ir de casa en casa sin que ninguna pudiera contenernos del todo, porque una parte nuestra siempre quedaba aquí, en estas calles..." (83) Su extranjería es manifestada de modos diferentes:

Todavía, a pesar de los meses transcurridos, yo me siento extraña, forastera, incapaz de sumarme a las marchas, al júbilo o la bronca de las manifestaciones. Apenas si puedo conmigo misma. Acepto esto como una debilidad, como el enfermo que después de una operación, comienza a caminar con cautela, paso a paso (68-69).

Meses antes de morir en enero 2003, Orgambide fue invitado a presentar una comunicación en un congreso de escritores judíos. Muy significativamente, el escritor condensó lúcidamente su motivación para escribir La convaleciente.

Terminada la dictadura, de regreso del exilio, para muchos comenzó una difícil etapa de readaptación al propio país, a la familia, el reaprendizaje de los vínculos y afectos maltratados. En La convaleciente intento, desde una narración contada en primera persona por una mujer, explicarme a mí mismo algunos de esos sentimientos, la sensación de extranjería que trae aparejado el desexilio. Esta novela tiene como protagonista a una argentina de origen judío, ex militante política que regresa del exilio. En su memoria aparece su padre muerto (a quien 
alguna vez lo llamaron “judío de mierda"), el torturador que le recordó su condición judía en la tortura y el tío Simón, hermano de su padre, sobreviviente de un campo de concentración, que aun goza de la vida (Orgambide 2004: 140-141; énfasis mío).

La "Carta a un padre" de E. Cozarinsky: filiación y diáspora lugar" de otros intelectuales judíos en el exilio voluntario. La experiencia vivida por el escritor y cineasta Edgardo Cozarinsky es bien ilustrativa. ${ }^{13}$ Hijo y nieto de judíos asquenazíes que se radicaron en la colonia agrícola entrerriana Clara, su total alejamiento de las tradiciones culturales y religiosas durante su largo autoexilio desde 1974 en Francia tuvo un momento de excepción: el encuentro con mujeres y ancianos en la ciudad puerto griego de Salónica en 1992, al escuchar por primera vez hablar en ladino. Allí confiesa que empezará a sentirse judío "cuando entendí que mi idioma me vinculaba con una tradición que había desconocido". Bien significativamente tituló ese texto con una pregunta, ¿Judío por hablar en castellano? (Cozarinsky, 2010: 62). El escritor confiesa con total sinceridad que su sentimiento de residir en la diáspora de argentinos que tuvieron que irse del país natal, le hizo descubrir otras diásporas anteriores de los suyos, y que hasta entonces eso nunca lo había comprendido. Dicho con sus propias palabras:

Creo que fue en ese momento cuando entendí que diáspora no hay una sola. Que mi pequeña experiencia, casi indolora, de una diáspora argentina, en mi caso cultural más que política, me hizo sensible a la de un pueblo que había vivido otra diáspora, impuesta cinco siglos atrás, por un estado triunfante, y que a través de esta sensibilidad recién adquirida empecé a entender la diáspora que yo había heredado, la de Europa del Este que hasta ese momento me había dejado más bien indiferente (Cozarinsky 2010: 62-63).

Pero al regresar a la Argentina, Cozarinsky va a descubrir otra faceta de la diáspora en la colonia rural donde el padre nació, transcurrió su infancia y los años jóvenes. El film que escribió y dirigió en 2014 sobre la juventud de su padre en Villa Clara, la mayor de las colonias agrícolas judías en la Provincia de Entre Ríos, lo tituló Carta a un padre. Pero a diferencia de la famosa carta de Kafka, en la suya el hijo no le reprocha la hipocresía y superficialidad del judaísmo paterno, sino procura indagar qué entendía su padre acerca de "lo judío" ${ }^{14}$ Lejos de rebelarse, el hijo anciano necesita entender aquellas preguntas que nunca alcanzó a formularle de niño a su padre, quien había abandonado la colonia agrícola a los 20 años para enrolarse en la marina de guerra argentina.

Las preguntas que entonces no me interesaba hacerle son las únicas que hoy me interesan. La primera: ¿cómo fue que ese hijo de gauchos judíos, nacido en Villa Clara, Villaguay, Entre Ríos, decidiera aventurarse a ingresar en las fuerzas armadas, en la Marina de guerra?

Una cosa me resulta evidente: fue posible porque ocurrió en 1919. A partir de 1930, desde el golpe de Uriburu, no creo que lo hubiesen aceptado.

¿Sabía mi padre, al ingresar, que no iba a poder ascender más allá de capitán de navío? Regla no escrita, gentlemen's agreement, un judío no podía llegar a ningún nivel del almirantazgo. Sobre todo: ¿le importaba?

Corolario: ¿qué significaba para él ser judío? No era religioso ni le importaba la tradición. Como a mi madre. A mí me criaron lejos de toda observancia. Creo que las únicas raíces que mi padre hubiese reconocido, aunque nunca hablara de ellas, estaban en Entre Ríos; entre sus libros encontré un ejemplar muy gastado de Entre Ríos, mi país de Gerchunoff. Cuando sintió que el fin se acercaba me pidió: "Por favor, ni estrella ni cruz, no vayan a creer que me convertí y eso no es elegante". ¿De dónde le venía esa noción de elegancia moral? (Cozarinsky 2016: 14-15) 
36

JCA del Baron de Hirsch), las preguntas que no alcanzó a formularle el hijo tienen que ver con la judeidad del padre y la del entorno rural de la colonia de chacareros judíos donde el abuelo y familia se asentaron ni bien arribaron en 1894, procedentes de la Gobernación Mohilne, en la región de Minsk; son preguntas de las que al cabo de muchos años también el hijo desea tener respuestas cuando visita por primera vez la comarca natal de los Cozarinsky, esa chacra con la casa del abuelo y de su padre juvenil; el impacto más fuerte ha de ser vislumbrar el borroso origen familiar rural de la familia paterna $y$, especialmente, la remota diáspora de sus antepasados judíos rusos: le conmueven las lápidas del cementerio de San Vicente, sobre todo aquellas donde el tiempo ha borroneado nombres y fechas.

En ellas leo las esperanzas de los inmigrantes fundadores, su desilusión, la tenacidad de los que permanecen fieles a las tierras que una vez les dieron en la colonia. Trato de imaginar el inimaginable orgullo de esos judíos del confín este de Europa al saberse propietarios de lo que más prohibido les estaba: la tierra (18).

Ahora bien: al origen diaspórico familiar de los suyos el escritor y cineasta lo resignifica, porque a pesar que no le interesa la tradición religiosa del judaísmo, ha de concluir que también él se siente miembro del pueblo del libro, a condición de "que no sea un texto sagrado":

Siempre me inspiró rechazo la religión judía, la crueldad del antiguo testamento, sus cientos de preceptos que rigen cada acto de la vida cotidiana; si en algo me reconocí judío es en una idea de diáspora no como maldición sino como privilegio, en no pertenecer a otra comunidad que a la de la gente del libro, de cualquier libro, siempre que no sea sagrado (19, énfasis mío).

Tal es el periplo y metáfora de la rebelión inconclusa y paradojal de los hijos nativos de padres y abuelos que conocieron la Emancipación en tierras latinoamericanas; la Carta a un padre de Cozarinsky revela que intelectuales judíos de su generación aprendieron a diasporizarse en el exilio, pero además, al regresar en plena era transnacional, se resisten a ver al Galuth como una maldición, transformándolo en un privilegio que le restituye el único territorio donde se sienten pertenecer: la comunidad del libro.

\section{BIBLIOGRAFÍA}

\section{Bibliografia citada y consultada}

Avni Haim, Judíos en América, Madrid, Mapfre, 1992.

Badinter Robert, Libres et égaux... L'émancipation des Juifs 1789-1791, Fayard, Paris, 1989.

Bello Alvarado y Rangel Marta, Etnicidad, "raza" y equidad en América latina y el Caribe, CEPAL, Documento de trabajo. 00-8-674, agosto 2000.

Cerruti Guldberg Horacio, Filosofar desde Nuestra América. Ensayo problematizador de su modus operandi, Prólogo Arturo Andrés Roig, (Colección Filosofía de Nuestra América), México, Miguel Ángel Porrúa/ CCYDEL, CRIM, UNAM, 2000.

Cuadernos LIRICO, 19 | 2018 
- Hacia una metodología de la historia de las ideas (filosóficas) en América Latina, Guadalajara, Universidad de Guadalajara, 1986.

--- Filosofía de la liberación latinoamericana. Presentación Leopoldo Zea, México, Fondo de Cultura Económica, 1983.

--- De varia utópica (Ensayos de utopía III). Presentación Luis Enrique Orozco, (Pensamiento Latinoamericano, ICELAC, 7), Bogotá, Universidad Central, 1989.

Cozarinsky Edgardo, Vudú urbano, Barcelona, Anagrama, 1985.

--- La novia de Odessa, Buenos Aires, Emece, 2001.

--- Lejos de dónde, Buenos Aires, Tusquets, 2009.

--- Blues, crónicas y memorias, Buenos Aires, Adriana Hidalgo, 2010.

--- Galaxia Kafka, Buenos Aires, Adriana Hidalgo, 2010.

--- La tercera mañana, Buenos Aires, Tusquets, 2011.

--- Dinero para fantasmas, Buenos Aires, Tusquets, 2012.

--- En ausencia de guerra, Buenos Aires, Tusquets, 2014.

--- Niño enterrado, Buenos Aires, Entropía, 2016.

Domínguez Michael Christopher, entrevista con Enrique Krause,"XIII y última. Enrique Krause y la conciencia liberal”. Letras Libres, 28 febrero 2011. Web. Consultado el 19 de julio de 2018.

Derrida Jacques, Y mañana qué. Diálogo con Élisabeth Roudinesco, Buenos Aires, FCE, 2003. Edición digital: Derrida en castellano.

--- “Abraham, l'autre”, en Judéités. Questions pour Jacques Derrida, Joseph Cohen et Raphael ZaguryOrly (dir.), Paris, Galilée, 2003: 11-42.

Di Stefano Roberto, "Por una historia de la secularización y de la laicidad en la Argentina", Quinto sol (Santa Rosa), 15, 1 (2011).

Girard Patrick, La Révolution Française et les Juifs, París, Robert Laffont, 1988.

Gómez Albino, Exilios (Por qué volvieron), Rosario, HomoSapiens - Editorial Tea, 1999.

Karady Victor, Los judíos en la modernidad europea. Experiencia de la violencia y utopía, Madrid, Siglo XXI, 2000.

Krauze Enrique, Siglo de Caudillos, México, Siglo XXI Editores, 1976.

--- Daniel Cosío Villegas: una biografía intelectual, México, Joaquín Mortiz,1980.

--- Caras de la historia (1983), México, Joaquín Mortiz, 1983.

--- Por una democracia sin adjetivos, México, Joaquín Mortiz-Planeta, 1986.

--- Biografía del poder, ocho volúmenes: I. "Porfirio Díaz. Místico de la autoridad"; II. "Francisco I. Madero. Místico de la libertad”; III. "Emiliano Zapata. El amor a la tierra”; IV. "Francisco Villa. Entre el ángel y el fierro"; V. "Venustiano Carranza. Puente entre siglos”; VI. "Álvaro Obregón. El vértigo de la victoria"; VII. Plutarco Elías Calles. Reformar desde el origen”; VIII. "Lázaro Cárdenas. General misionero", México, Fondo de Cultura Económica, 1987.

--- Personas e ideas, México, Vuelta, 1989.

--- Textos heréticos, México, Grijalbo, 1992.

--- Siglo de caudillos: Biografía Política de México (1810-1910), México, Tusquets, 1994. 
--- Mexico: Biography of Power: A History of Modern Mexico, 1810-1996, New York, Harper Collins Publishers, 1997.

--- La presidencia imperial, México, Tusquets, 1997.

--- De héroes y mitos, Mexico,Tusquets, 2010.

Marti Alejandro y Radowitzky Simon, Del atentado a Falcón a la Guerra Civil Española, La Plata, De la Campana, 2010

Michelletti Maria Gabriela, "Inmigración y religión en Santa Fe: ¿unidad nacional y de creencias o liberalismo cosmopolita?”, Épocas - revista de historia, USAL, núm. 3, dic. 2010, p. 133-164.

Mizraje María Gabriela, “Una retórica del cruce: Lazos de sangre en los textos identitarios de Germán Rozenmacher”, Sambatión. Estudios judíos desde Latinoamérica1,2006, p. 78-101.

Mosès Stéphane, El Ángel de la Historia. Rosenzweig, Benjamín, Scholem, Madrid, Cátedra, 1997.

Navarrete Alonso Roberto, La galut en el pensamiento de Franz Rosenzweig: disimilación del judaísmo y ciudadanía alemana en la República de Weimar, paper presentado en el workshop "Diaspora/Exilio, Ciudadanía y Deber de Memoria”, Instituto H. Truman (Universidad Hebrea de Jerusalén, Consejo Superior Instituto de Investigaciones Cientificas (CSIC), Jerusalén, p. 13-14, diciembre 2015.

Navarrete Alonso Roberto, "Franz Rosenzweig y la crisis del historicismo alemán", Pensamiento. Revista de investigación e información filosófica, LXXI, 265, 2015, p. 117-135.

Orgambide Pedro, Historia con tangos y corridos, Casa de las Américas, La Habana, 1976.

--- Aventuras de Edmund Ziller en tierras del Nuevo Mundo, novela, Grijalbo, México, 1977.

--- El Arrabal del mundo, Buenos Aires, Bruguera,1983a.

--- "Notas sobre un poema de Humberto Costantini", Hispamérica, año 12, No. 36, dic. 1983, p. 45-49.

--- Hacer la América, Bruguera, Bueno Aires, 1984.

--- Pura memoria, Buenos Aires, Bruguera, 1985a.

--- Todos teníamos veinte años, Buenos Aires, Pomaire, 1985b.

--- Gardel y la patria del mito, Buenos Aires, Legasa, 1985c.

--- La Convaleciente, Buenos Aires, Legasa, 1987.

--- Cuentos con tango, Buenos Aires, Ameghino, 1988.

--- Mujer con violoncello, Buenos Aires, Beas, 1993.

--- Ser argentino, Buenos Aires-Montevideo-Santiago de Chile, Temas, 1996.

--- “Aprendimos a ser extranjeros", en Jorge Boccanera, Tierra que anda, Los escritores en el exilio, Buenos Aires, Ameghino, 1999, p. 151-162.

--- La Bella Otero: reina del variete, Buenos Aires, Sudamericana, 2001.

--- Un tango para Gardel, Buenos Aires, Sudamericana, 2003 (póstumo).

--- "La literatura en tiempos de intolerancia, identidad y narración", Ricardo Feierstein, Recreando la cultura judeoargentina, II, Buenos Aires, Milá, 2004, p. 137-41.

Oviedo Gerardo, "Horacio C. Guldberg, lector de Ezequiel Martínez Estrada. Praxis utópica y ensayo latinoamericano", CECIES. Pensamiento latinoamericano y alternativo. Web. Consultado el 19 de julio de 2018. 
Rapoport Nicolás, Desde lejos y hasta ayer, Buenos Aires, edición propia, 1957.

--- La Querencia (entre arroyos y cuchillas), Buenos Aires, Samet, 1929.

Roniger Luis, Senkman Leonardo, Sznajder Mario, Sosnowski Saúl, Exile, Diaspora, and Return: Changing Cultural Landscapes in Argentina, Chile, Paraguay and Uruguay, Oxford University Press, 2017.

Rozenmacher German, Réquiem para un viernes a la noche, Buenos Aires, Talía, 1971, 2da. ed.

Schwartzmann Turkenich Félix (1913-2014) Memoria Chilena, Biblioteca Nacional, Web. Consultado el 19 de julio de 2018.

Schwartzmann Turkenich Félix, El sentimiento de lo humano en América, Santiago de Chile, Universidad, Facultad de Filosofía y Educación, Instituto de Investigaciones Histórico-Culturales, 2 vols. 1953.

Senkman Leonardo, "The Latin American Diasporas: New Collective Identities and Citizenship Practices”, in Mario Sznajder, Luis Roniger and Carlos A. Forment (eds.) Shifting Frontiers of Citizenship: The Latin American Experience, Leiden-Boston, Brill, 2013, Brill, p. 385-410.

Seiguer Paula, "Religión y formas de producción de etnicidad. La Iglesia Anglicana en la Argentina”, en Rodríguez, Ana María (ed.), Estudios de historia religiosa argentina (siglos XIX y XX), Rosario, Prohistoria-EdUNLPam, 2013.

Sznajder Mario y Roniger Luis, La política del destierro y el exilio en América Latina, México, Fondo Cultura Económica, 2013.

Yankelevich Pablo, Ráfagas de un exilio: argentinos en México, 1974-1983, México, El Colegio de México, 2009.

Zehnder Sabina, Poética espacial de la diáspora y del exilio en la trilogía de la memoria de Pedro Orgambide, Paraná, La Hendija, 2015.

\section{NOTAS}

1. El Estado se limitó a laicizar algunas instituciones a causa de la irreversible pluralización religiosa de una sociedad inmigratoria aluvial. La Iglesia Católica en Argentina seguirá siendo una institución de derecho público como el Estado y las demás instituciones religiosas quedarán confinadas al plano del derecho privado junto a los clubes deportivos o las sociedades mutuales de los inmigrantes. Con ello se sancionaba la desigualdad jurídica de los cultos y se reconoció al catolicismo como cuasi oficial. Ver Roberto Di Stefano (2011).

2. Comparar las memorias de ambiente urbano de Nicolás Rapoport, Desde lejos y hasta ayer (1957, p.10-12, 53-61) y los relatos campestres de su libro anterior de cuentos, La Querencia (entre arroyos y cuchillas) 1929.

3. La pobreza y marginalidad de los pueblos indígenas y afrolatinos tiene su origen en factores socioculturales y económicos de larga data histórica donde la discriminación étnico-racial juega un papel central como fuente de exclusión de la ciudadanía y pobreza y marginalidad para dichas poblaciones (Bello \& Rangel 2000).

4. Félix Schwartzmann Turkenich escribió su tesis sobre antropología filosófica, titulada El sentimiento de lo humano en América: ensayo de antropología filosófica, premio municipal de ensayo 1951. Tras publicar entre 1951 y 1953 El sentimiento de lo humano en América en dos volúmenes, Schwartzmann escribió numerosos ensayos de corte estético-filosófico y de filosofía de la ciencia. Desde 1956, y durante más de 20 años, dirigió la Revista de Filosofía de la Universidad de Chile, y 
asumió distintas responsabilidades en esa misma institución. Durante el proceso de Reforma Universitaria redactó la Declaración de Principios de la Universidad de Chile, que constituyó en su momento la base filosófica y programática de esa universidad.; ninguna crónica biográfica del filósofo menciona su origen judío (ver Félix Schwartzmann Turkenich Memoria Chilena, Biblioteca Nacional).

5. http://dcsh.izt.uam.mx/cen_doc/cefilibe/images/banners/enciclopedia/Diccionario/Autores/ Filosofos, acceso 12/6/2017. En 2006 le fue otorgado a Cerruti Guldberg el grado de Doctor Honoris Causa, por la Universidad "Ricardo Palma", Lima, Perú, "por sus contribuciones para el desarrollo de una filosofía humanística latinoamericana". Ver Oviedo.

6. "Con el tiempo he llegado a pensar y a entender que el haberme formado -desde el kínder hasta la preparatoria- en el Colegio Israelita, donde recibí una formación no religiosa pero sí cultural amplia en el humanismo judío, tuvo una influencia indudable en mi visión de historiador. Te diré algo evidente: la Biblia puede verse como una biografía del poder y como una biografía del saber; es una sucesión de reyes, de caudillos, de jueces y de profetas. Bien vista, es la historia del pueblo de Israel narrada alrededor de esas figuras magnéticas, desde Abraham hasta Salomón" ( Domínguez Michael, 2011).

7.

8. Pedro Orgambide, El Arrabal del mundo (1983), Hacer la América (1984) y Pura memoria (1985); véase un estudio literario que analiza esta trilogía desde el abordaje de la diáspora en Sabrina Zehnder (2015).

9. El día antes de morir, la edición dominical Cultura y Nación del diario Clarin, (19.1.2003) publicaba "El nono y el zeide", colaboración de Pedro Orgambide para su columna semanal.

10. Véanse, entre otros libros de Pedro Orgambide, Historia con tangos y corridos, 1976; Gardel y la patria del mito,1985; Cuentos con tango ,1988; La Bella Otero: reina del variete, 2001 y la última novela póstuma editada a los tres meses de morir, Un tango para Gardel, 2003.

11. Pedro Orgambide participó junto con otros exiliados argentinos en México de un volumen titulado Veinte cuentos del exilio (1983), compilado por su amigo Humberto Costantini; sobre el exilio político en México, ver Yankelevich (2009).

12. Véase también la entrevista en Gómez (1999: 127-130).

13. Escritor, guionista, director de cine y crítico literario, Edgardo Cozarinsky (Buenos Aires, 1939) emigró a Paris en 1974, en pleno terror del loperreguismo y la Triple A, luego de publicar su primer libro de ensayo Borges y el cine. Desde entonces, su producción como cineasta desplazó a la creación literaria, a pesar del éxito de Vudu Urbano (1985, prólogo de Susan Sontag y Guillermo Cabrera Infante). A partir de su decisión en 1989 de retornar en forma gradual a Buenos Aires, se transforma en un nomadic sojourne, publicando sus obras literarias más difundidas y premiadas: $\mathrm{La}$ novia de Odessa (2001), El rufian moldavo (2004), Maniobras nocturnas (2007), Lejos de dónde (2009), La tercera mañana (2011). Simultáneamente, durante esos mismos años publicó ensayos y crónicas: El pase del testigo (2001), Milongas, crónicas y cuentos ( 2006), Blues, crónicas y ensayos (2008); Burundanga, humor (2009). Corresponden además a esos años del regreso la filmación y guión de Tango deseo (2002), La quimera de los héroes (2003), Ronda nocturna (2005), también sus films autobiográficos Apuntes para una biografia imaginaria (2010) ; Carta a un padre (2014).

14. El film Carta a un padre se estrenó en 2014. Ver la entrevista de Roger Koza a Edgardo Cozarisnky y publicado en el Blog del Departamento.Audiovisual del Museo de Arte Contemporaneo Buenos Aires, el 26 de mayo 2015, https:// audiovisualmacba.wordpress.com/2015/05/26/carta-a-un-padre-de-edgardo-cozarinsky/. La Carta a un padre se publicó bajo el título Eastros en el libro de apostillas de Cozarinsky, Niño enterrado, Buenos Aires, 2016. Todas las citas corresponden a esta edición. 


\section{RESÚMENES}

El ensayo analiza primeramente las diferencias histórico-culturales del proceso de emancipación social y cívica de los judíos en Europa respecto de la experiencia en América Latina a fin de exponer de modo comparativo ciertos rumbos disímiles que algunos intelectuales nativos hijos de inmigrantes judíos a América Latina protagonizaron en situaciones conflictivas familiares respecto de los hijos de padres judíos emancipados en el Viejo Mundo, según la caracterización de Stéphane Mosès. Esta primera parte de necesaria contextualización permite luego repensar el proceso de disasimilación de dos escritores judeoargentinos que habían sido forzados al exilio durante los años de autoritarismo en su país, quienes al sentirse despojados de la nación y ciudadanía, ofrecen testimonios autobiográficos sobre diáspora e inasimilación en los años de errancia y también luego a su regreso a la tierra natal.

Cet article analyse d'abord les différences historiques et culturelles du processus d'émancipation sociale et citoyenne des juifs d'Europe en le confrontant à l'expérience en Amérique latine afin d'exposer, de manière comparative, certaines directions spécifiques dont quelques intellectuels fils et filles d'immigrants juifs en Amérique latine ont été les protagonistes, dans des situations familiales conflictuelles en regard des enfants de parents juifs émancipés du Vieux Continent, selon la caractérisation de Stéphane Mosès. Cette première partie consacrée à une nécessaire contextualisation permet de repenser ensuite le processus de désassimilation de deux écrivains judéo-argentins qui avaient été forcés à l'exil durant les années d'autoritarisme dans leur pays, lesquels, en se sentant dépouillés de la nation et de la citoyenneté, offrent des témoignages autobiographiques sur la diaspora et l'inassimilation dans leurs années d'errance et aussi ensuite lors de leur retour à leur terre natale.

This article first deals with historical and cultural differences between the European and South American Jews' emancipation process in order to comparatively show how some intellectuals, daughters and sons of South American Jewish immigrants have been the main actors on both social and citizen-like aspects, in some conflicted family situations in respect to children born from Jewish parents emancipated from the old Continent, according to Stéphane Mosès's definition. This first part is dedicated to a necessary contextualization to make room to rethink the deconstructing of the assimilation process of two Jewish Argentinians that have been forced into exile during the dictatorship years of the country and whom, feeling dispossessed of both their country and citizenship, give autobiographical accounts on their diaspora and their integration failure during their years of roaming but also after they have returned to their motherland.

\section{ÍNDICE}

Mots-clés: Émancipation, judéité, inassimilation, exil, diaspora

Palabras claves: Emancipación, judeidad, inasimilación, exilio, diáspora

Keywords: Wmancipation, Jewish identity, assimilation, failure, exile, diaspora 
AUTOR

LEONARDO SENKMAN

Universidad Hebrea de Jerusalén 